\title{
Inclusive Education as Exclusive Practice: One Parent's Experience Advocating for Children with Fetal Alcohol Spectrum Disorders Within the School System
}

\author{
Bathseba Opini \\ University of British Columbia
}

\begin{abstract}
Fetal alcohol spectrum disorder (FASD) is a significant cause of cognitive and developmental disability among children in Canada, with accompanying lifelong risks to independent living. Previous studies have called for improved home-school collaboration to support children with FASD, but barriers remain for parents seeking collaborative involvement. Using a narrative approach, this article presents one parent's experiences advocating for children with FASD within a school system in central Canada. Emerging narrative themes were schools' lack of knowledge and awareness of FASD, the difficulty of choosing a school or program, and the importance of listening to parents and families. Within the context of previous findings, this parent's narrative confirms and makes urgent key areas of need for improved support of children with FASD. These include improved training for teachers and administrators, flexible accommodations including specialized environments when needed, and above all an active commitment to trusting collaborations and encouragement of parental involvement.
\end{abstract}

Fetal alcohol spectrum disorder (FASD) is one of the leading causes of cognitive and developmental disability among children in Canada (Anderson, 2015; Ontario Centre of Excellence for Child and Youth Mental Health [OCECYMH], 2014). FASD is a diagnostic term describing the constellation of effects that result from prenatal alcohol exposure, which includes physical, behavioural, emotional, adaptive, and neurocognitive disabilities (Anderson, 2015; Cook et al., 2015; Coons, Watson, Yantzi, Lightfoot, \& Larocque, 2017; Pei, Tremblay, McNeil, Poole, \& McFarlane, 2016). FASD can affect memory, sensory integration, social communication, language processing, emotional regulation, adaptive 
functioning, and other executive functions such as planning, prioritizing, organizing, paying attention, and remembering details (Duquette, Stodel, Fullarton, \& Hagglund, 2007). These effects have implications for an individual's emotional well-being, social inclusion, and academic and vocational success (Anderson, 2015). The prevalence of FASD in Canada is not accurately known, but estimates of 9-10 cases per 1,000 people are often used (Public Health Agency of Canada, 2003, cited in Popova, Lange, Bund, \& Rehm, 2016, p. 368). In 2013, the estimated overall costs associated with FASD in Canada were $\$ 1.8$ billion (Coons, Watson, Schinke, \& Yantzi, 2016).

The literature suggests that given the effects of FASD on the executive, socioemotional, memory, and adaptive functions, many children with the condition may be unable to live independently or to secure and maintain employment later in life. They are less likely to be able to manage money or to parent children (Healthy Child Manitoba, 2017). The likelihood of experiencing serious behavioural problems and conflict with the law as adults is also high (Anderson, 2015). The probability of children with FASD experiencing difficulties later in life compared to those without FASD warrants prompt intervention at an early age (Healthy Child Manitoba, 2017; TCHP Education Consortium, 2000). One key area in which to implement interventions and supports is the education system. However, parents, teachers, or schools cannot offer these interventions alone; there has to be collaboration between the parents and the school.

Epstein (1995) observed that for schools to make a difference in enhancing student learning, a team effort involving teachers, students, and parents is essential. Across Canada, provincial and territorial ministries of education, school boards, and schools encourage greater parental partnership and involvement to promote academic success. These efforts include volunteerism, language interpreter services, mentoring, and fundraising (Epstein, 1995, 2001; Kidder, 2011). There is a need for parents to become more involved in schools to support their children. What is often ignored is the fact that for parents with children with FASD or other learning limitations, successful involvement in and partnerships with schools are sometimes impossible without the support of school administrators and teachers. Even when these parents try to provide for the needs (physical, social, emotional, mental, and spiritual) of their children, the likelihood of meaningful progress is limited if schools fail to work hand in hand with them. Thus, for children with FASD, parent-home-school collaborations aimed at ensuring adequate support, care, and the provision of basic human rights are crucial (Ewles, Clifford, \& Minnes, 2014).

This paper seeks to contribute to the existing literature by examining one parent's experiences in collaborating with educators and advocating for her children with FASD. It is hoped that sharing these experiences will shed light on the barriers confronting such parents and at the same time inspire both parents and educators to collaborate in supporting children with FASD within the school system.

\section{Understanding Parental Advocacy}

Advocacy means speaking up for oneself or others (Atkinson, Cooper, \& Ferris, 2006). It is a non-violent empowerment and support process through which families with children with disabilities can constructively express dissatisfaction and contribute to 
creative solutions to problems in human service systems (Field, 1996; Munro, 1991). Advocacy involves activities such as gathering information and problem solving and, in the case of parents or guardians of children with disabilities, involvement in public education, political activism, and speaking on behalf of their child or other children with disabilities (Ewles et al., 2014). Parental advocacy is often driven by the need to address some problem or concern relating to their child or children; some difficulty concerning special education; anger about a new policy being introduced; or a collective effort to create a new service or program (Kidder, 2011). The problem in school systems is often a lack of proper support for children with disabilities and their families. Since their roles and needs evolve, these families need supports in order to avoid loss of control and responsibility in caring for their children (Alper, Schloss, \& Schloss, 1995).

For children with disabilities, elementary and middle school present unique challenges and opportunities to learn academic skills, discover how to access resources, engage in social interaction, and develop friendships (Alper et al., 1995). If children are to succeed during these years, parents have to work with various professionals, teachers and school administrators included (Alper et al., 1995; Morningstar, Turnbull \& Turnbull, 1995). For parents to advocate effectively, they need to know relevant social, economic, and political environments and become familiar with philosophies of service delivery, legislation, and budgetary issues (Baskin, Delja, Mogil, Gorospe, \& Paley, 2016; Ewles et al., 2014).

Test, Fowler, Wood, Brewer, \& Eddy (2005) identified four steps of advocacy that are useful for understanding parental experiences in advocating for children with FASD. These steps do not necessarily occur in isolation but often overlap. The first step has to do with the parent(s) acquiring knowledge of the child's disability, in addition to his or her interests, preferences, strengths, needs, and learning style (Hutchinson et al., 2014; Test et al., 2005). The parent(s) judge the impact of the disability on the child's academic and social performance and identify strategies that might enhance his or her performance (Test et al., 2005). Some parents acquire the requisite information from experience, others from conferences, friends, peers, support groups, reading relevant literature, online and otherwise, from medical authorities, or a combination of these (Baskin et al., 2016; Hutchison et al., 2014). As a result, they learn a great deal about FASD and in the process become disability experts (Trainor, 2010). When parents possess knowledge and insights regarding their child's disability they can work toward becoming intuitive advocates (Trainor, 2010).

Test et al. (2005) emphasized that parents ought to understand their children's rights. In Canada, the rights of people with disabilities are spelled out in the Canadian Charter of Rights and Freedoms and the Canadian Human Rights Act. Section 15(1) of the Canadian Charter of Rights and Freedoms, the Equality Rights section, guarantees persons with disabilities the right to equal protection and equal benefits without discrimination by government, their agents, and delegates. This section of the Charter also protects persons with mental disabilities (Government of Canada, 2016). The Human Rights Act prohibits discrimination against persons with disabilities (Government of Canada, 1985; 2016). Additionally, provinces and territories have human rights commissions that address discrimination, stigmatization, and social exclusion of people with disabilities. By 
understanding their child's rights, parents will possess the knowledge and skills, if not the social capital, to work the system (Kidder, 2011).

Parental advocacy also necessitates having knowledge of the child's disability and his or her rights and being able to communicate that knowledge effectively (Test et al., 2005). In order to communicate their feelings, needs, and desires assertively, parents must negotiate, persuade, compromise, listen, and both use and read body language. Some prefer to communicate face to face, others by written communication (Hutchison et al., 2014). Knowing and communicating that knowledge also involves strategizing. Parents must understand the special education process from the referral for evaluation and identification of a disability through the development of an individualized education program (IEP). Sometimes when parents become strategists, school authorities view them unfavourably because they know too much and hold teachers accountable for their child's IEP (Trainor, 2010).

Lastly, advocacy is leadership. Test et al. (2005) asserted that leadership is all about learning group roles and dynamics and the skills required to function within groups. Leadership may require active involvement in preparing an IEP or recognizing the role of various team members in this process. It also involves parents forming support groups or joining advocacy groups in which they share experiences with other parents and learn how to lobby for support and services at the local, national, and international levels (Hutchison et al., 2014). This is not an easy task, for as Alper et al. (1995) observed, systems are exceedingly difficult to change even under constant pressure. Educators and schools in general would benefit from working collaboratively with parents or guardians of children with disabilities. Schools' failure to listen to and involve parents makes parents feel isolated and insecure about their children's education. The practice of listening includes things like inviting parents to participate in preparation of their children's individual education program (IEP) and discussing with them ways and means to implement it (Eason \& Whitbread, 2006; Ontario Ministry of Education, 2010). As Milsom (2006) suggested, it could also involve answering parents' questions with a positive attitude and explaining what is happening in the school, both in and out of class.

\section{Research Literature}

Much of the existing research on FASD has focused on its nature, manifestations, and incidence (Barth, 2001; Besinger, Garland, Litrownik, \& Landsverk, 1999; Culhane, Webb, Grim, Metraux, 2003; Health Canada, 2004; O’Malley, 2007; Thanh, Jonsson, Salmon, \& Sebastianski, 2014); issues of diagnosis (Chudley et al., 2005; Clarren \& Lutke, 2008; Cook et al., 2015; Salmon \& Clarren, 2011); parenting and/or fostering children with FASD (Doelling \& Johnson, 1990; McFadden, 1996; Olson, Oti, Gelo, \& Beck, 2009; Paley, O’Connor, Frankel, \& Marquardt, 2006); training for parents of children with FASD (Burry, 1999; Weiner \& Morse, 1994); social skills of children with FASD (O'Connor et al., 2006; Thomas, Kelly, Mattson, \& Riley, 1998); pharmacological and non-pharmacological interventions (Bertrand, 2009; Coe, Sidders, Riley, Waltermire, \& Hagerman, 2001; Kalberg \& Buckley, 2007; Reid et al., 2015); needs of persons with FASD (Brackenreed, 2013); and school persistence for children and youth with FASD (Duquette et al., 2007; Duquette \& Stodel, 2005; Johnson \& Lapadat, 2000). 
Few studies look at facilitating parental collaborations and partnerships with schools and enhancing the skills of teachers and administrators working with children with FASD within and outside the school. The limited research that does exist emphasizes the merits of collaboration among parents of children with FASD, but little is said about parents trying to engage in such efforts at the school level. For example, Streissguth (1997) called for school-based FASD support teams that would study and catalogue students' individual learning styles and ways to increase advocacy, collaboration, and support among caregivers, community professionals, and organizations. Brown, Sigvaldason, and Bednar (2005) examined the needs of foster parents in successful placements of children with FASD. Brown et al. found that parents value responsive professionals willing to treat them with respect and collaborate in advocating for their children. Kalberg and Buckley (2006) noted that meaningful collaborations occur when families with children with FASD actively participate in developing and implementing school programs because professionals move in and out of the children's lives and are thus unable to follow them over the entirety of their education. Parents or guardians should play an integral part in the educational planning so that their needs and those of their children can be accommodated. The school team and family should work together to develop, assess, and refine the child's school program throughout his or her school years (Kalberg \& Buckley, 2006).

Green (2007) analyzed interventions for supporting children with FASD in school settings and acknowledged the need for caregivers, health professionals, and teachers and administrators to have the skills and knowledge required to respond to the needs of affected children. Green (2007) called for collaboration between parents or caregivers and professionals to support students with FASD in achieving their academic, social, emotional, and behavioural goals. Duquette et al. (2007) confirmed the importance of collaboration in providing learners with FASD supportive learning environments, particularly during the early years of schooling, to increase the likelihood of their graduating from high school and succeeding later in life. Bertrand (2009) seconded this observation when examining individualized and targeted interventions for children with FASD in the United States. Bertrand (2009) reaffirmed that collaboration throughout the entire learning process is fundamental to the success of intervention programs.

In the few studies examining the experiences of parents of children with FASD in Canada, Swart, Hall, McKee, and Ford (2014) acknowledged the importance of meaningful communication and collaboration between school personnel and caregivers as well as of teachers' knowledge to ensure success for children affected by FASD in schools. Job et al. (2013) found that educational professionals lack sufficient awareness of both FASD and effective teaching strategies to address it. Lack of knowledge impedes professionals in providing appropriate programs for students with FASD and engaging collaboratively with their families. Similar conclusions were drawn by Green et al. (2014), who found that parents and caregivers often feel marginalized or blamed for their children's difficulties in school because professionals lack both knowledge of FASD and the skills to cope with it. Baskin et al. (2016) reported that caregivers of children with FASD were cognizant of the barriers they face, including lack of time, money, and energy. Many feel isolated and yearn to connect with other parents and share common experiences (Baskin et al., 2016). These studies demonstrate the need for strong 
collaborations, yet little is known about the experiences of parents when seeking to collaborate with schools.

\section{Methodology}

Informed by a narrative approach, this article uses data generated from an ongoing project that focuses on parental advocacy for children with disabilities. Five parents or guardians of children who had a disability and who were enrolled in the public school system in central Canada were asked to share their experiences working with the schools to support their children. The two questions that guided the conversations were: "What kinds of experiences do parents and guardians of children with disabilities have when collaborating with schools and advocating for students with disabilities?" and "How might schools work closely with parents and guardians to enhance inclusive schooling for children with disabilities?"

Clandinin and Connelly (2000) noted that a narrative approach is most suitable for capturing detailed stories or life experiences of a single life, or of the lives of a small number of individuals. People construct stories based on their lived experiences. They give those stories meaning and sometimes use them as a form of social action. For these reasons, narratives or stories convey people's inner feelings, perceptions, and interpretations of their lived experiences (Moen, 2006). Clandinin and Connelly (2000) added that narrative researchers situate individual stories within participants' personal experiences, their cultures, and their historical contexts. Narratives provide opportunities for researchers to listen to, and gain understanding of, the lived experiences of the study participants (Ronksley-Pavia \& Grootenboer, 2017). Knowledge gained from the participants' narratives is useful in making sense of the complexity of human lives.

This narrative study involved individually interviewing each of the five parents or guardians over the phone for 45 to 60 minutes. The interviews were audiotaped and later transcribed verbatim. I reviewed the transcriptions and grouped the emerging ideas into themes in order to provide a nuanced discussion of the stories that the participants had shared (Huber \& Whelan, 1999). The transcripts were sent to the interviewees for cross-checking.

This paper focuses on the voice of Sue (a pseudonym), the only parent in the study who had children with FASD. As Gale and Densmore (2003) observed, concentrating on one key participant "allows for a coherent storyline to emerge" (p. 37). In this case, the storyline is about advocacy and the role of the parent in the advocacy process. Through an in-depth analysis of Sue's story and the existing literature, I discuss her experiences of trying to advocate for, and to collaborate with the school system to support, her children with FASD.

\section{Narrative Experiences}

Sue is a racialized parent living in a large city in central Canada. She has four children aged eight, ten, eleven, and twelve years, who are enrolled in a public school and all of whom have FASD. The children are in grades four, six, seven, and eight respectively. Sue's narrative provides insights into the complex terrain she has to 
navigate within the school system. Her experiences are summed up using three themes: lack of knowledge and awareness of FASD; difficulties in selecting the "right" schools and programs for her children; and challenges related to convincing the schools to listen to parental input.

\section{Lack of Knowledge and Awareness of FASD}

One of the most frustrating experiences for Sue was the fact that the teachers and other staff lacked sufficient knowledge and awareness of FASD. They did not understand the diverse ways in which FASD plays out, and this lack of knowledge affected how they perceived children with FASD and how they worked to support their learning:

You know these children have invisible disabilities, and people make all kinds of assumptions. Physically you cannot see the disability, you cannot see the children's brains, and they are not living with the children to see how their behaviours play out. It is such a distinctive disability. It is frustrating, when you talk about having behavioural challenges; even the experts do not understand, the people that work on the front line every day. They lack a lot of knowledge and awareness of FASD. That is why they make many assumptions. If my children do not show the behaviour they are looking for then they do not have a disability.

Sue understood her children's disability, how it manifested itself, and how it affected their learning. She was frustrated by the fact that the teachers had little knowledge about FASD and made assumptions about her children that affected service provision and support. This lack of knowledge has been attributed to limited systematic research on the needs of children with FASD and on effective learning strategies to enhance their learning (Blackburn, 2009; Ryan \& Ferguson, 2006). Since FASD symptoms and outcomes fall along a continuum and may also be invisible, it was hard for some educators to believe Sue when she was advocating for her children and seeking to collaborate. The children's physical appearance may have suggested nothing unusual, especially for people who did not fully understand FASD. As a result, teachers often misread verbal cues and actions, even when Sue shared with them what she believed was the correct interpretation:

The child will go up to the teacher and say, "I like your dress," "I like your shoes," "I like your this," "I like your that." And the teacher will write a note back home saying: "Oh, she says really nice words." But it is not that she is saying nice words; that is part of the social ineptitude that comes with her disability; she likes to be the centre of attention. So she will develop strategies to be always centre of attention. If it means telling the teacher all the time that "I like your dress" or wanting to be the teacher's helper, then she is getting attention. The teachers make assumptions because of lack of knowledge about FASD and lack of awareness about the diversity in the disability and what the disability means. It can be very diverse; that is why it is a spectrum.

Children with FASD may appear fluent but fail to understand the meaning of the words they use. Here, one of Sue's children was using words without necessarily comprehending what they meant. The teachers did not look at the child's statements critically and therefore could not redirect the child's behaviour. Sue found that educators' lack of knowledge about FASD made persuading them to provide school accommodations for her children difficult. She noted: "Getting a designation for my 
children was in itself a challenge because no one had a grasp of what was going on. Nobody seemed to believe me when I told them that these children have a disability."

One of the key challenges in supporting children with FASD in schools is the difficulty of getting a designation. This is because ministries of education across the country recognize particular categories of special needs, while other exceptionalities are not recognized (Duquette \& Orders, 2010). Ultimately, Sue obtained a secondary diagnosis in order for her children to qualify for support and resources. To be an effective advocate for her children, Sue had to work around a crucial diagnostic gap. The existence of an FASD classification would have greatly improved the support her children received

Sue provided additional examples of how the teachers' limited understanding of FASD led them to misinterpret her children's behaviours, even when they were at risk of serious harm:

There was a time when one of my children banged her head, and she had this huge bump and she did not cry. Then they said stuff like, "Wow, she is such a good girl." Yeah, she is such a good girl, but there are serious underlying issues here: She does not cry because she does not process and feel pain as others do, which has implications. This shows the teachers' lack of awareness of FASD.

The teachers assumed that the student was just strong and brave, when in reality those with FASD process bodily sensations poorly owing to neurological impairment (Healthy Child Manitoba \& Manitoba Education, Citizenship and Youth, 2009). The teachers failed to recognize that the child did not cry for the very reason that she did not process pain. Sue's experience with her child's injury illustrates the practical and emotional challenges faced by parents attempting to form trusting partnerships with teachers who are unaware of the symptoms and outcomes of FASD.

More disappointing for Sue was the fact that schools assumed that any teacher with special education training would know about FASD, when this was not necessarily the case:

Even in the special needs schools there are people there who do not understand FASD. When I was in [name of school], the children changed classes a few times... They would hire a special education teacher, but that did not necessarily mean they had an understanding of FASD.... They tend to think that a disability is just a disability; they are all the same. They lump the needs of people who have a disability into one large group, and this is wrong.

Through her experience advocating for her children with FASD, Sue understood that disability is diverse. She saw that having a special education teacher on staff did not necessarily mean they would understand FASD because of the limited number of people with specialized training in the public education system.

Sue pointed to everyday lived experience as a unique and valuable way of learning about FASD. Having lived experience does not necessarily mean having a child with FASD; it could also entail living, or spending time with, or caring for someone with FASD:

In my experience with children with this specific disability, the only people that truly understand my situation ... and ... possess in-depth knowledge of it are those in support groups and other parents or caregivers of children with FASD. Without lived experiences of this kind of disability, one can never truly understand it. You can never fully understand its 
dynamics from books. The one person who I met and who was an expert in it, and really understood it was this gentleman in [name of city].... I discovered that he understood it because he had family members who had it. So when people in your family have it and you get to live with them and see, you get a clear picture of what I am talking about. Look, my brother could say, "Oh, I have a sister with children that have FASD," but he will have no grasp of it because we don't live together. He doesn't know how it plays out; he can only hear the stories I tell him ... people have a very linear notion of what disability is. Majority of the time they think it has to be physical and they have to see it.

People with lived experiences of FASD have firsthand knowledge and therefore tend to have a better understanding of the disability. Sue's real-life experiences provided her important lessons about FASD.

\section{Selecting Schools and Programs}

Many parents seek to ensure that the school to which they send their children is the right fit for them. Sue took the time to research schools that would cater to her children's social, emotional, and academic needs. This also meant making careful choices about their extracurricular activities:

You want to be very careful about the kind of school you send your children to. Even if I want to send my children to summer camp, I have to be careful where to send them. It is not just a matter of sending them to any summer camp; you have to send them to a camp that has sensory equipment, for example, because they have very severe sensory needs. I find that the best kind of environment for my children is one that caters to children with autism.

Sue spoke to the significance of addressing the sensory needs of her children. Children with FASD are highly sensitive to sensory stimulation. The little things occurring in their environment often upset them. They may be sensitive to and become easily distracted by odours, light, and noise (Chudley et al., 2005; Healthy Child Manitoba \& Manitoba Education, Citizenship and Youth, 2009). Sue observed that sometimes teachers with a good understanding of autism were more likely to work better with her children due to their sensory needs:

And so a teacher that understands autism may not be aware so much of FASD, but they share so many similar characteristics that it is better to send your children to such a teacher or environment. FASD, I believe, shares some of the characteristics of autism, especially sensory characteristics. Roughly, the same kind of equipment and the same or similar learning environment is applicable for both conditions. Therefore, everything that I do in life has a purpose. Everything that I do for my children, from the very clothes they wear to the food that they eat, is carefully thought out because of their disability that no one else can see or often understand but me.

Other areas Sue struggled with were routines or programming and diet. Children with FASD do well when routines are strictly maintained. Any change to a routine must be preceded by a great deal of advance warning (Developmental Services Resource Centre-Kitchener, n.d.; FASD Support Network of Saskatchewan, n.d.; Healthy Child Manitoba \& Manitoba Education, Citizenship and Youth, 2009; Healthy Child Manitoba, 2017). Foods like cookies are packed with additives and sugar that are unhealthy and also, as some have argued, albeit inconclusively, affect children's concentration (Bellisle, 
2004). Nevertheless, Sue faced challenges when she notified teachers about her children's routines and dietary preferences:

When you have the school running routines that are contrary to what parents do at home, the parents feel undermined. How can you get the children to listen to you? At home, you insist no sugary stuff, as these things work them up. I send notes to the teachers, asking, begging, and pleading with them not to give the children these things. It is almost like they don't care. At one point this one teacher told me, "Oh, she refused to eat her lunch, so I gave her cookies." Some children with FASD will not show their behaviour at school, and when they get home they let it out. Simple things like watching the foods they eat make a huge difference. It is frustrating when the school, or I should say teachers, don't listen. I understand they have 20-plus other children to attend to, but here I am spending time talking to them about it and they say it is fine, but they do otherwise. It is like the child is a number to help them get funding. They are not listening to the parents.

Consistency, whether at home or school, is important for children with FASD; yet, as Sue revealed, this seems not to be happening. She was disappointed because the educators, even when informed about the adverse effects of certain foods, still gave those foods to the children.

A related struggle had to do with homework. As FASD is a spectrum condition, those affected may work on tasks, including homework, in different ways. It was difficult for Sue to convince the teachers as to the appropriate amount of homework to assign to her children and the best way(s) to structure it:

I wish they would listen, this homework thing is useless. It does not help them in any way. When they bring work home every day, if the teachers understood their needs, they would assign homework only on Fridays because when they come home from school, they are overstimulated and cannot concentrate. As they walk through the door, the rules they followed at school are discarded. And that is a key characteristic of some of the children that have FASD. They tend to hold things in until they get in an environment where they are really comfortable. Of course, even a child without these challenges will act differently and listen to the teacher and follow the rules more readily than they would in the presence of their parents in the home environment. It is challenging when you communicate with teachers and nothing changes.

Supervising homework for children with FASD can be complicated given that they are prone to hyperactivity, are easily distracted, and find it difficult to process information, among other things (Healthy Child Manitoba \& Manitoba Education, Citizenship and Youth, 2009). Sue's awareness of these challenges led to her remarks about how and when homework was assigned. Sue preferred that teachers structure tasks in a manner that the children could easily follow.

\section{Listening to Parents and/or Families}

As Sue emphasized repeatedly, listening to parents is important for creating familyfriendly schools, and especially for supporting parents of children with disabilities like FASD. In some cases, listening involves teachers and administrators acknowledging what they do not know, committing to finding answers, and supporting parents in addressing the needs of their children. Sue noted: 
Even if you don't understand the disability, it is okay to acknowledge that you do not, but please listen to the parents because they have expertise. Experience is the best teacher. So teachers, administrators, and parents need to work collaboratively. Schools should consult with parents on everything they do.

Sue reiterated that parents have an important role to play in the development of school programs for children with FASD and can contribute toward bettering their children's learning experiences. Parents appreciate it when their input, knowledge, and values are considered in the decision-making processes. Although it can be difficult collaborating with school administrators, those who are supportive can make a huge difference in the lives of the children and parents:

Although it can be challenging, the good news is that even if you have a principal that does not have a lot of understanding about FASD, it is good that they are supportive of you. One positive and supportive person or experience can make a difference in the lives of these children. I find that when I am working with the schools and my children, everything the administrators say is what happens.

Sue highlighted the significance of lobbying for services and support and of winning the support and co-operation of principals and vice-principals, given that often what they say is what goes. School administrators have far more power to influence outcomes than teachers do. They are very much the managers of organizational meaning, the custodians of organizational legitimacy, and the definers of organizational and social reality (Anderson, 1990; Leithwood, Janzi, \& Steinbach, 1999). Sue felt that if school administrators collaborated and supported parents of children with FASD, much more could be done to enhance the children's experiences and overall academic success.

On occasion, Sue sensed that although the school system claimed to want parents to participate actively in their children's learning, they only wished this to happen to a limited degree. Asking critical questions meant that she was considered pushy. Sue observed:

I realized they don't like it when you ask questions. The administration was flabbergasted and frustrated when I was on top of things. I asked about services, and explained what works and what doesn't work for the children. Their body language says it all; they don't even hide it. It is as if I am this troublemaker making their lives hard.

Sue perceived that her knowledgeable advocacy for her children made the teachers and administrators uncomfortable. Adding to the complexity, she sensed that, as a racialized parent, her efforts to undermine the stereotypical notion that racialized parents are often hard to reach and less likely to participate in their children's education, had struck a raw nerve. This is a case where doing good makes one feel bad. The educators' response discomforted Sue, leading her to conclude that her activism had branded her a troublemaker. To her, the school staff's body language conveyed the impression that, in their view, she was invading their professional territory.

\section{Discussion}

This paper has endeavoured to make sense of one parent's experience advocating for students with FASD within the school system in Canada. Sue's experiences offer a snapshot of the complexities involved in advocating for children with FASD. The 
findings illustrate ways in which raising and educating children with FASD is exceedingly difficult. Sue often confronted challenges associated with school professionals' lack of knowledge and awareness of FASD; challenges in choosing schools and programs in which her children should participate; and frustration in trying to work with school authorities that may not necessarily listen to and tap into her expertise as a parent.

Sue's experiences reflect what existing studies (Blackburn, Carpenter, \& Egerton, 2010; Green, 2007; Job et al., 2013; Koren, Fantus, \& Nulman, 2010; OCECYMH, 2014) have said about educators in the school system lacking knowledge about FASD. There is a lack of systematic training and preparation for teachers at the pre-service and in-service levels to work with children affected by FASD (Job et al., 2013). Although public and government awareness of FASD in Canada has been increasing, along with clinical awareness, funding, and FASD diagnostic capability (Kyskan \& Moore, 2005; Government of Ontario, 2017), it has yet to inform the school system. It is especially challenging for teachers and other support staff to meet the complex learning and behavioural support needs of children with FASD when they lack the requisite knowledge and skills. Children with FASD present challenges for educators who need to address uneven learning profiles and opportunities that can only be addressed by developing individual curricula and planning tasks centred around the student's strengths and interests as identified in a comprehensive assessment (Blackburn, Carpenter, \& Egerton, 2012; Kalberg \& Buckley, 2007). It is important that school districts update their practices and policies accordingly (see OCECYMH, 2014) so as to equip teachers with the skills to support children with FASD.

Sue referred to the need for greater collaboration between the school and parents or guardians of children with FASD (Epstein, 1995; Kidder, 2011). She believed that parents could offer important insights, informed by their lived experiences, for developing programs for children with FASD. Sue's wish was for teachers and administrators to work closely with parents when making decisions about program development and support services for children with FASD (Alper et al., 1995; Duquette et al., 2007; Kalberg \& Buckley, 2006; Swart et al., 2014).

Learning support and planning for children with FASD entails flexible accommodation approaches and at times a need for specialized FASD classrooms (Blackburn et al., 2012; Chudley et al., 2005; Kalberg \& Buckley, 2006; Millar et al., 2017). This may be necessary in situations in which, for example, a student with FASD is worked up and providing a quiet clutter-free personal space could help him or her calm down (Carpenter, 2011). Making available the necessary supports requires policy development, sustained funding, political will, staff training, evidence-informed practice, individualized educational planning, and collaborative partnerships between schools, clinical and non-clinical professionals, families, and the community (Blackburn et al., 2012; OCECYMH, 2014). To achieve all this, it is imperative that schools collaborate with parents. Having teachers and administrators who are willing to listen and collaborate, regardless of the scarcity of resources, relieves parents of a great deal of stress.

Sue raised the question of how much parental involvement is reasonable. An important consideration for schools, and which requires further exploration, is for 
educators to reflect on their understanding and interpretation of parental advocacy and ways schools might welcome this advocacy to better support the learning needs of children with FASD. Sue's narratives demonstrate her desire to speak on behalf of her children (Atkinson et al., 2006). She wished to share the knowledge and the lived experiences she has (see Hutchinson et al., 2014; Test et al., 2005) with the school in order to help address the needs of her children. Sue sensed that her advocacy had run up against a brick wall. Her experience illustrates how judgmental attitudes on the part of school authorities can damage the relationship between schools and parents striving to support children with disabilities (Christenson, 2004; Gettinger \& Guetschow, 1998).

\section{Limitations and Conclusion}

Although Sue's single narrative provides important lessons about advocating for children with FASD within the school system, it is difficult to generalize the results to other parents because of the small sample size. There is a need for further studies involving a larger sample size to allow for a better understanding of the experiences of other parents. In spite of these limitations, this exploration of Sue's efforts to advocate for her children with FASD shows the range and complex impact of the barriers that such parents encounter. If advocacy is to succeed, as noted earlier, improved collaboration between parents and schools is essential (Duquette et al., 2007). Teachers' knowledge of FASD is also fundamental. Previous studies have called for better training at teachers' colleges and for continued professional development to provide teachers with the knowledge and skills to better recognize and support affected students (Bertrand, 2009; Caley, Kramer, \& Robinson, 2005; Dybdahl \& Ryan, 2009). Educators should keep in mind that FASD is a spectrum disorder and its manifestations can vary with each child. This recognition is important when planning for and implementing teaching and learning strategies for students with FASD. It will also assist school authorities in collaborating with caregivers, in addition to reducing mistrust and the tendency to be judgmental, if they understand that each child's needs are unique (Job et al., 2013).

Educators need to take a closer look at their relations with parents and guardians of children with disabilities. When parents or guardians ask questions, it is not necessarily a bad thing. They are hoping to be listened to and to obtain advice and resources, along with the reassurance that their children are receiving a quality education. Moreover, there has to exist a consensus between schools and parents regarding how best to support students with disabilities. Parents of children with special needs often feel isolated and uncertain about their children's education and overall future (Lemacks, Fowles, Mateus, $\&$ Thomas, 2013). Strong and trusting collaborations and partnerships can help them develop a sense of belonging and of being supported both within schools and in the wider community (Moles, 1997; Smith, 2003).

Creating opportunities for parents of children with FASD to participate in their children's education is vital. There is a need for structured collaboration and partnership between schools and parents. For example, beyond convening identification, placement, and review committee (IPRC) meetings on a regular basis, much more could be done to help parents become more involved in the education process. If possible, practices such as home visits by teachers would enable educators to witness how children with FASD 
behave in an environment outside of the school. Additionally, as Christenson (2004) suggested, schools should consider positive ways of sharing information with parents, along with other more flexible practices, such as setting up meetings with parents of children with disabilities and, where possible, assisting them in sharing their experiences and supporting one another.

\section{References}

Alper, S., Schloss, P. J., \& Schloss, C. N. (1995). Families of children with disabilities in elementary and middle school: Advocacy models and strategies. Exceptional Children, 62(3), 261-270.

Anderson, G. (2015). Fetal alcohol spectrum disorder: Provincial roundtable report to the Minister of Children and Youth Services. Retrieved from http://www.children.gov.on.ca/htdocs/English /documents/specialneeds/fasd/FASD_Roundtable_Report.pdf

Anderson, G. L. (1990). Toward a critical constructivist approach to school administration: Invisibility, legitimating, and the study of non-events. Educational Administration Quarterly, 26(1), 38-59.

Atkinson, D., Cooper, M., \& Ferris, G. (2006). Advocacy as resistance: Speaking up as a way of fighting back. In D. Mitchell et al. (Eds.). Exploring experiences of advocacy by people with learning disabilities: Testimonies of resistance (pp. 13-19). London, UK: Jessica Kingsley.

Barth, R. P. (2001). Research outcomes of prenatal substance exposure and the need to review policies and procedures regarding child abuse reporting. Child Welfare, 80(2), 275-296.

Baskin, J., Delja, J. R., Mogil, C., Gorospe, C. M., \& Paley, B. (2016). Fetal alcohol spectrum disorders and challenges faced by caregivers: Clinicians' perspectives. Journal of Population Therapeutics and Clinical Pharmacology, 23(2), e114-e130.

Bellisle, F. (2004). Effects of diet on behaviour and cognition in children. British Journal of Nutrition, 92(2), S227-S232. Retrieved from https://www.natuurarts.nl/downloads/bellisle-sugar-andcognition-in-children-2004.pdf

Bertrand, J., \& Interventions for Children with Fetal Alcohol Spectrum Disorders Research Consortium. (2009). Interventions for children with fetal alcohol spectrum disorders (FASDs): Overview of findings for five innovative research projects. Research in Developmental Disabilities, 30(5), 986-1006.

Besinger, B. A., Garland, A. F., Litrownik, A. J., \& Landsverk, J. A. (1999). Caregiver substance abuse among maltreated children placed in out-of-home care. Child Welfare, 78(2), 221-239.

Blackburn, C. (2009). Early learning and fetal alcohol spectrum disorders. EYE Magazine, 11(4) 38-44.

Blackburn, C., Carpenter, B. \& Egerton J. (2010). Shaping the future for children with fetal alcohol spectrum disorders. British Journal of Learning Support, 35(3), 136-145.

Blackburn, C., Carpenter, B., \& Egerton, J. (2012). Educating children and young people with fetal alcohol spectrum disorders: Constructing personalised pathways to learning. New York, NY: Routledge.

Brackenreed, D. (2013). Needs of persons with FASD: A descriptive case study. American International Journal of Contemporary Research, 3(9), 51-63.

Brown, J. D., Sigvaldason, N., \& Bednar, L. M. (2005). Foster parent perceptions of placement needs for children with a fetal alcohol spectrum disorder. Children and Youth Services Review, 27(3), 309-327.

Burry, C. L. (1999). Evaluation of a training program for foster parents of infants with prenatal substance effects. Child Welfare, 78(1), 197-214. 
Caley, L. M., Kramer, C., \& Robinson, L. K. (2005). Fetal alcohol spectrum disorder. The Journal of School Nursing, 21(3), 139-146.

Carpenter, B. (2011). Pedagogically bereft! Improving learning outcomes for children with fetal alcohol spectrum disorders. British Journal of Special Education, 38(1), 37-43.

Chudley, A. E., Conry, J., Cook, J. L., Loock, C., Rosales, T., \& LeBlanc, N. (2005). Fetal alcohol spectrum disorder: Canadian guidelines for diagnosis. Canadian Medical Association Journal, 172(5), S1-S21.

Christenson, S. L. (2004). The family-school partnership: An opportunity to promote the learning competence of all students. School Psychology Review, 33(1), 83-104.

Clandinin, D. J., \& Connelly, F. M. (2000). Narrative inquiry: Experience and story in qualitative research. San Francisco, CA: Jossey-Bass.

Clarren, S. K., \& Lutke, J. (2008). Building clinical capacity for fetal alcohol spectrum disorder diagnoses in western and northern Canada. Canadian Journal of Clinical Pharmacology 15(2), e223-e237.

Coe, J., Sidders, J., Riley, K., Waltermire, J., \& Hagerman, R. (2001). A survey of medication responses in children and adolescents with fetal alcohol syndrome. Mental Health Aspects of Developmental Disabilities, 4, 148-155.

Cook, J. L., Green, C. R., Lilley, C. M., Anderson, S. M., Baldwin, M. E., Chudley, A. E., ... Mallon, B. F. (2015). Fetal alcohol spectrum disorder: A guideline for diagnosis across the lifespan. Canadian Medical Association Journal, 188(3), 191-197.

Coons, K. D., Watson, S. L., Schinke, R. J., \& Yantzi, N. M. (2016). Adaptation in families raising children with fetal alcohol spectrum disorder, Part I: What has helped. Journal of Intellectual and Developmental Disability, 41(2), 150-165.

Coons, K. D., Watson, S. L., Yantzi, N. M., Lightfoot, N. E., \& Larocque, S. (2017). "No alcohol is recommended, but ...": Health care students' attitudes about alcohol consumption during pregnancy. Global Qualitative Nursing Research, 4, 1-12.

Culhane, J. F., Webb, D., Grim, S., \& Metraux, S. (2003). Prevalence of child welfare services involvement among homeless and low-income mothers: A five-year birth cohort study. Journal of Sociology and Welfare, 30(3), 79-95.

Developmental Services Resource Centre-Kitchener (n.d.). Routine and consistency-Fetal Alcohol Spectrum Disorder [Web page]. Retrieved from https://www.fasdwaterlooregion.ca /strategies-tools/sub-page-test-2/routine-and-consistency

Doelling, J. L., \& Johnson, J. H. (1990). Predicting success in foster placement: The contribution of parent-child temperament characteristics. American Journal of Orthopsychiatry, 60(4), 585-593.

Duquette, C. \& Orders, S. (2010). Toward a provincial strategy: Advancing effective educational practices in fetal alcohol spectrum disorders (FASD). Dryden, ON: FASD-ONE Intervention and Support Working Group. Retrieved from http://www.fasdontario.ca/cms/wpcontent/uploads/2014/01/Toward-a-Provincial-Strategy-Advancing-Effective-EducationalPractices-2010.pdf

Duquette, C., \& Stodel, E. J. (2005). School experiences of students with fetal alcohol spectrum disorder. Exceptionality Education Canada, 15(2), 51-75.

Duquette, C., Stodel, E., Fullarton, S., \& Hagglund, K. (2007). Secondary school experiences of individuals with fetal alcohol spectrum disorder: Perspectives of parents and their children. International Journal of Inclusive Education, 11(5-6), 571-591. 
Opini

Dybdahl, C. S., \& Ryan, S. (2009). Inclusion for students with fetal alcohol syndrome: Classroom teachers talk about practice. Preventing School Failure: Alternative Education for Children and Youth, 53(3), 185-196.

Eason, A. I. \& Whitbread, K. (2006). IEP and inclusion tips for parents and teachers. Verona, WI: IEP Resources. http://www.faslink.org/IEPTips.pdf

Epstein, J. L. (1995). School/family/community partnerships: Caring for the children we share. Phi Delta Kappan, 76, 701-712.

Epstein, J. L. (2001). School and family partnerships: Preparing educators and improving schools. Boulder, CO: Westview.

Ewles, G., Clifford, T., \& Minnes, P. (2014). Predictors of advocacy in parents of children with autism spectrum disorders. Journal on Developmental Disabilities, 20(1), 73-82.

FASD Support Network of Saskatchewan. (n.d.). FASD tips for parents and caregivers. Numbers 120. Retrieved from https://lcfasd.com/wp-content/uploads/2017/07/FASD-Tips-for-Parentsand-Caregivers-1-20.pdf

Field, S. (1996). Self-determination instructional strategies for youth with learning disabilities. Journal of Learning Disabilities, 29(1), 40-52.

Gale, T., \& Densmore, K. (2003). Engaging teachers: Towards a radical democratic agenda for schooling. Maidenhead, UK: Open University Press.

Gettinger, M., \& Guetschow, K. W. (1998). Parental involvement in schools: Parent and teacher perceptions of roles, efficacy, and opportunities. Journal of Research and Development in Education, 32(1), 38-52.

Government of Canada. (1985). Human Rights Act. Retrieved from http://lawslois.justice.gc.ca/eng/acts/h-6/fulltext.html

Government of Canada. (2016). Rights of people with disabilities (Webpage). Ottawa, ON: Author. Retrieved from http://www.canada.pch.gc.ca/eng/1448633334025

Government of Ontario. (2017). Strengthening healthcare. Toronto, ON: Ontario Ministry of Finance. Retrieved from http://www.fin.gov.on.ca/en/budget/ontariobudgets/2017/ch4a.html

Green, C. R., Roane, J., Hewitt, A., Muhajarine, N., Mushquash, C., Sourander, A., ... Reynolds, J. N. (2014). Frequent behavioural challenges in children with fetal alcohol spectrum disorder: A needs-based assessment reported by caregivers and clinicians. Journal of Population Therapeutics and Clinical Pharmacology, 21(3), e405-e420.

Green, J. H. (2007). Fetal alcohol spectrum disorders: Understanding the effects of prenatal alcohol exposure and supporting students. Journal of School Health, 77(3), 103-108.

Health Canada. (2004). Fetal alcohol spectrum disorder: A framework for action. Retrieved from http://www.hc-sc.gc.ca.ezproxy.library.ubc.ca/dca-dea/publications/fasd-

etcaf/framework_e.html

Healthy Child Manitoba. (2017). Every day is an adventure: What parents and caregivers need to know about FASD. Winnipeg, MB: Government of Manitoba. Retrieved from https://www.gov.mb.ca/healthychild/fasd/fasd_caregivers.pdf

Healthy Child Manitoba \& Manitoba Education, Citizenship and Youth. (2009). What educators need to know about FASD: Working together to educate children in Manitoba with fetal alcohol spectrum disorder. Winnipeg, MB, Canada. Retrieved from https://www.gov.mb.ca /healthychild/fasd/fasdeducators_en.pdf

Huber, J. \& Whelan, K. (1999). A marginal story as a place of possibility: Negotiating self on the professional knowledge landscape. Teaching and Teacher Education, 15, 381-396. 
Hutchinson, N. L., Pyle, A., Villeneuve, M., Dods, J., Dalton, C. J., \& Minnes, P. (2014). Understanding parent advocacy during the transition to school of children with developmental disabilities: Three Canadian cases. Early Years, 34(4), 348-363.

Job, J. M., Poth, C. A., Pei, J., Cassie, B., Brandell, D., \& Macnab, J. (2013). Toward better collaboration in the education of students with fetal alcohol spectrum disorders: Integrating the voices of teachers, administrators, caregivers, and allied professionals. Qualitative Research in Education, 2(1), 38-64.

Johnson, C. L., \& Lapadat, J. C. (2000). Parallels between learning disabilities and fetal alcohol syndrome/effect: No need to reinvent the wheel. Exceptionality Education Canada, 10(3), 65-81.

Kalberg, W. O., \& Buckley, D. (2006). Educational planning for children with fetal alcohol syndrome. Annali-Istituto Superiore Di Sanita, 42(1), 58-66.

Kalberg, W. O., \& Buckley, D. (2007). FASD: What types of intervention and rehabilitation are useful? Neuroscience \& Biobehavioural Reviews, 31(2), 278-285.

Kidder, A. (2011). Parent advocacy: The good, the bad, and the ugly. Education Canada, 54, 1-6. Retrieved from http://eric.ed.gov/?id=EJ946429

Koren, G., Fantus, E. \& Nulman, I. (2010). Managing fetal alcohol spectrum disorder in the public school system: A needs assessment pilot. Canadian Journal of Clinical Pharmacology, 17(1), 79-89.

Kyskan, C. E., \& Moore, T. E. (2005). Global perspectives on fetal alcohol syndrome: Assessing practices, policies, and campaigns in four English-speaking countries. Canadian Psychology, $46(3), 153-156$.

Leithwood, K., Jantzi, D., \& Steinbach, R. (1999). Changing leadership for changing times. Buckingham, UK: Open University Press.

Lemacks, J., Fowles, K., Mateus, A., \& Thomas, K. (2013). Insights from parents about caring for a child with birth defects. International Journal of Environmental Research and Public Health, $10(8), 3465-3482$.

McFadden, E. J. (1996). Family-centered practice with foster-parent families. Families in Society: The Journal of Contemporary Social Services, 77(9), 545-558.

Millar, J. A., Thompson, J., Schwab, D., Hanlon-Dearman, A., Goodman, D., Koren, G., \& Masotti, P. (2017). Educating students with FASD: Linking policy, research and practice. Journal of Research in Special Educational Needs, 17(1), 3-17.

Milsom, A. (2006). Creating positive school experiences for students with disabilities. Professional School Counseling Journal, 10(1), 66-72. Retrieved from http://www.readingrockets.org /article/creating-positive-school-experiences-students-disabilities

Moen, T. (2006). Reflections on the narrative research approach. International Journal of Qualitative Methods, 5(4), 56-69.

Moles, O. C. (Ed.). (1997). Reaching all families: Creating family-friendly schools. U.S. Department of Education, Office of Educational Research and Improvement. Retrieved from http://files.eric.ed.gov/fulltext/ED400117.pdf

Morningstar, M. E., Turnbull, A. P., \& Turnbull, H. R. (1995). What do students with disabilities tell us about the importance of family involvement in the transition from school to adult life? Exceptional Children, 62(3), 249-260.

Munro, J. D. (1991). Training families in the "Step Approach Model" for effective advocacy. Canada's Mental Health, 39, 1-6. 
Opini

O’Connor, M. J., Frankel, F., Paley, B., Schonfeld, A. M., Carpenter, E., Laugeson, E. A., \& Marquardt, R. (2006). A controlled social skills training for children with fetal alcohol spectrum disorders. Journal of Consulting and Clinical Psychology, 74(4), 639-648.

Olson, H. C., Oti, R., Gelo, J., \& Beck, S. (2009). "Family matters:" Fetal alcohol spectrum disorders and the family. Developmental Disabilities Research Reviews, 15(3), 235-249.

O'Malley, K. D. (2007). ADHD and fetal alcohol spectrum disorders (FASD). New York, NY: Nova Publishers.

Ontario Centre of Excellence for Child and Youth Mental Health (OCECYMH). (2014). Mental health service provision in schools for children with fetal alcohol spectrum disorder. Toronto, ON: Author. Retrieved from http://www.excellenceforchildandyouth.ca/sites/default /files/eib_attach/FASDClinicalServices_FINAL_REPORT.pdf

Ontario Ministry of Education. (2010). Parents in partnership: A parent engagement policy for Ontario schools. Toronto, ON: Author. Retrieved from http://www.edu.gov.on.ca /eng/parents/involvement/PE_Policy2010.pdf

Paley, B., O'Connor, M. J., Frankel, F., \& Marquardt, R. (2006). Predictors of stress in parents of children with fetal alcohol spectrum disorders. Journal of Developmental \& Behavioural Pediatrics, 27(5), 396-404.

Pei, J., Tremblay, M., McNeil, A., Poole, N., \& McFarlane, A. (2017). Neuropsychological aspects of prevention and intervention for FASD in Canada. Journal of Pediatric Neuropsychology, $3(1), 25-37$.

Popova, S., Lange, S., Burd, L., \& Rehm, J. (2016). The economic burden of fetal alcohol spectrum disorder in Canada in 2013. Alcohol and Alcoholism, 51(3), 367-375.

Public Health Agency of Canada. (2014). Evaluation of the fetal alcohol spectrum disorder initiative 2008-2009 to 2012-2013. http://www.phac-aspc.gc.ca/about_apropos/evaluation/reportsrapports/2013-2014/efasdi-eietaf/index-eng.php\#a4.1

Reid, N., Dawe, S., Shelton, D., Harnett, P., Warner, J., Armstrong, E., ... O'Callaghan, F. (2015). Systematic review of fetal alcohol spectrum disorder interventions across the life span. Alcoholism: Clinical and Experimental Research, 39(12), 2283-2295.

Ronksley-Pavia, M., \& Grootenboer, P. (2017). Insights into disability and giftedness: Narrative methodologies in interviewing young people identified as twice exceptional. In R. Dwyer, I. Davis, \& E. Emerald (Eds.), Narrative research in practice (pp. 183-207). Singapore: Springer.

Ryan, S., \& Ferguson, D. L. (2006). On, yet under, the radar: Students with fetal alcohol spectrum disorder. Exceptional Children, 72(3), 363-379.

Salmon, A., \& Clarren, S. K. (2011). Developing effective, culturally appropriate avenues to FASD diagnosis and prevention in northern Canada. International Journal of Circumpolar Health, $70(4), 428-433$.

Smith, P. M. (2003). You are not alone: For parents when they learn their child has a disability. News Digest, 20(3), 2-6. Retrieved from http://www.familyvoices.org/admin/work_caring /files/nd20.pdf

Streissguth, A. P. (1997). Fetal alcohol syndrome: A guide for families and communities. Baltimore, MD: Paul H. Brookes Publishing.

Swart, S., Hall, W. A., McKee, W. T., \& Ford, L. (2014). Caregivers' management of schooling for their children with fetal alcohol spectrum disorder. Qualitative health research, 24(11), $1540-1552$.

TCHP Education Consortium. (2000). Fetal alcohol syndrome. Retrieved from http://www.faslink.org/FASbook2.pdf 
Test, D. W., Fowler, C. H., Wood, W. M., Brewer, D. M., \& Eddy, S. (2005). A conceptual framework of self-advocacy for students with disabilities. Remedial and Special Education, $26(1), 43-54$.

Thanh, N. X., Jonsson, E., Salmon, A., \& Sebastianski, M. (2014). Incidence and prevalence of fetal alcohol spectrum disorder by sex and age group in Alberta, Canada. Journal of Population Therapeutics and Clinical Pharmacology, 21(3), e395-e404.

Thomas, S. E., Kelly, S. J., Mattson, S. N., \& Riley, E. P. (1998). Comparison of social abilities of children with fetal alcohol syndrome to those of children with similar IQ scores and normal controls. Alcoholism: Clinical and Experimental Research, 22(2), 528-533.

Trainor, A. A. (2010). Diverse approaches to parent advocacy during special education home school interactions: Identification and use of cultural and social capital. Remedial and Special Education, 3(1), 34-47.

Weiner, L., \& Morse, B. A. (1994). Intervention and the child with FAS. Alcohol Research and Health, 18(1), 67-72.

\section{Authors' Note}

Correspondence concerning this article should be addressed to Bathseba Opini, Department of Educational Studies, Faculty of Education, University of British Columbia Education Centre at Ponderosa Commons, 6445 University Boulevard, Vancouver, BC, V6T 1Z2, Canada. Email: bathseba.opini@ubc.ca 